\title{
Epidemiology of Interdialytic Ambulatory Hypertension and the Role of Volume Excess
}

\author{
Rajiv Agarwal \\ Indiana University School of Medicine and Richard L. Roudebush Veterans Administration Medical Center, \\ Indianapolis, Ind., USA
}

\section{Key Words}

Ambulatory blood pressure monitoring $\cdot$ Epidemiology $\cdot$ Epoetin $\cdot$ Hemodialysis $\cdot$ Hypertension $\cdot$ Vitamin D receptor activators

\begin{abstract}
Background: The epidemiology of hypertension among hemodialysis (HD) patients is difficult to describe accurately because of difficulties in the assessment of blood pressure (BP). Methods: Using 44-hour interdialytic ambulatory BP measurements, we describe the epidemiology of hypertension in a cohort of 369 patients. To seek correlates of hypertension control, antihypertensive agents were withdrawn among patients with controlled hypertension and ambulatory BP monitoring was repeated. Results: Hypertension (defined as an average ambulatory systolic BP $\geq 135 \mathrm{~mm} \mathrm{Hg}$ or diastolic $\mathrm{BP} \geq 85 \mathrm{~mm} \mathrm{Hg}$, or the use of antihypertensive medications) was prevalent in $82 \%$ of the patients and independently associated with epoetin use, lower body mass index and fewer years on dialysis. Although $89 \%$ of the patients were being treated, hypertension was controlled adequately in only $38 \%$. Poor control was independently associated with greater antihypertensive drug use. Inferior vena cava (IVC) diameter in expiration was associated with increased risk of poorly controlled hypertension both in
\end{abstract}

cross-sectional analysis and after withdrawal of antihypertensive drugs. Conclusions: Interdialytic hypertension is highly prevalent and difficult to control among HD patients. End-expiration IVC diameter is associated with poor control of hypertension in cross-sectional analyses as well as after washout of antihypertensive drugs. Among HD patients, an attractive target for improving hypertension control appears to be the reduction of extracellular fluid volume.

Copyright $\odot 2011$ S. Karger AG, Basel

\section{Introduction}

Among hemodialysis (HD) patients, the epidemiology of hypertension has been described using blood pressure (BP) recordings that are either measured immediately before or after dialysis [1-4]. However, peridialytic measurements may not reflect recordings during the interdialytic interval [5]. Furthermore, studies have shown that compared to peridialytic recordings, interdialytic BP measurements are not only more powerful determinants of target organ damage [6] but also stronger predictors of

The study was supported by NIH 2R01-DK062030-07.

\section{KARGER}

๑) 2011 S. Karger AG, Basel

Fax +41613061234 E-Mail karger@karger.ch www.karger.com 
all-cause mortality $[7,8]$. Thus, the epidemiology of hypertension needs to be assessed using interdialytic ambulatory BP recordings. Also, although there is general acceptance among nephrologists that expanded extracellular fluid volume (ECFV) is directly related to the control of hypertension [9], the relationship between expanded ECFV and difficult-to-control hypertension has not been rigorously tested.

This study has two parts. The first part of the study describes the prevalence, treatment, and control of hypertension using interdialytic ambulatory $\mathrm{BP}$ recordings; comparison is then made between the epidemiology of ambulatory hypertension with that of hypertension ascertained by pre- and postdialytic BP recordings. The second part of the study ascertains the role of expanded ECFV on the control of hypertension. This association is assessed in two ways. First, the relationship between hypertension control and ECFV using echocardiographic evidence of volume excess is established. Second, antihypertensive medications are gradually withdrawn to test whether an expanded ECFV is associated with the development of hypertension using 44-hour interdialytic ambulatory $\mathrm{BP}$ recordings.

\section{Patients and Methods}

The study has a cross-sectional design. The washout of antihypertensive drugs had a longitudinal design.

\section{Participants}

Although portions of this cohort have been described previously $[6,10]$, the epidemiology of ambulatory hypertension has never been reported from these participants. Patients $\geq 18$ years who had been on chronic HD for $>3$ months and were free of vascular, infectious or bleeding complications within 1 month of recruitment and who were dialyzed three times a week at one of the four dialysis units in Indianapolis affiliated with Indiana University were enrolled in the study between October 2003 and March 2011. Drawn from a pool of $500 \mathrm{HD}$ patients at any time, these patients are predominantly African-Americans and underserved. Those who missed $\geq 2$ HD treatments over 1 month, abused drugs, had either chronic atrial fibrillation or body mass index $(B M I) \geq 40$ were excluded. Patients who had a change in dry weight or antihypertensive drugs within 2 weeks were also excluded. The study was approved by the Institutional Review Board of the Indiana University and the Research and Development Committee of the Roudebush VA Medical Center, Indianapolis, and all subjects gave written informed consent.

\section{Measurements}

Ambulatory BP Monitoring

Ambulatory BP monitoring (ABPM) was performed either after the first or mid-week HD sessions for $44 \mathrm{~h}$. Using an appropriately sized cuff, ambulatory $\mathrm{BP}$ was recorded every 20 min during the day (6 a.m. to 10 p.m.) and every 30 min during the night (10 p.m. to 6 a.m.) using a Spacelab 90207 ambulatory blood pressure monitor (SpaceLabs Medical Inc., Redmond, Wash., USA) in the non-access arm, as reported previously [11]. In this study, patients with $<8$ h of ambulatory BP recordings were noted to have inadequate measurement and were excluded.

Dialysis Unit Blood Pressures

Dialysis unit BP recordings measured by the dialysis unit staff before and after dialysis were collected prospectively at the time of the patient visit. These BP recordings were obtained using a sphygmomanometer equipped with $\mathrm{HD}$ machines without a specified technique. These devices measure BP using an oscillometric technique, but no validation of these devices has been published. BP recordings were averaged over 2 weeks; thus, for routine dialysis unit BP monitoring, each patient had 6 BP measurements recorded before and 6 after dialysis.

Echocardiograms

Two-dimensional (2D)-guided M-mode echocardiograms were performed by research echocardiographic technicians, 3060 min following dialysis, in the dialysis unit with a digital cardiac ultrasound machine (Cypress Acuson; Siemens Medical). The postdialytic period was selected for echocardiography as it allows control over the volume state of the patient since it is associated with the least intravascular volume. The day following dialysis would be associated with a variable change in the dimensions of the inferior vena cava (IVC) and left atrium (LA) depending on the state of volume expansion and was not chosen for echocardiography.

The protocol-specified recording of at least 6 cycles of $2 \mathrm{D}$ parasternal long- and short-axis views with optimal orientation of the cursor beam was used to derive additional M-mode recordings. Each patient underwent $6 \mathrm{M}$-mode measurements of IVC in inspiration and expiration, and LA diameter in end systole using standards of the American Society of Echocardiography [12]. All measurements were made over 6 cardiac cycles by a highly skilled echocardiographer and confirmed by an experienced cardiologist.

IVC was imaged at the level just below the diaphragm in the hepatic segment by $2 \mathrm{D}$-guided, M-mode echocardiography. IVC diameter was measured just before the $\mathrm{P}$ wave of the electrocardiogram during end expiration and end inspiration while avoiding Valsalva-like maneuvers. Although its value for treating individual patients has never been studied, IVC diameter is responsive to dry-weight reduction and therefore a marker of ECFV excess [13].

The LA diameter indexed for body surface area has also been shown to be a marker of volume and therefore, along with IVC diameter, it was chosen as ECFV marker for this analysis [13].

\section{Definitions of Hypertension Prevalence, Treatment, and \\ Control}

Prevalent Hypertension

First hourly average ambulatory BP was computed and averaged over the $44 \mathrm{~h}$ of recording to yield the overall ambulatory BP. Ambulatory BP values $\geq 135 / 85 \mathrm{~mm} \mathrm{Hg}$ were considered hypertensive [14]. Although lower BP values have been suggested as thresholds to diagnose hypertension, for the sake of consistency with previous work among HD patients, the JNC 7 recommenda- 
tions for the diagnosis of ambulatory hypertension were followed. Similarly, pre- and postdialytic BP recordings were averaged over 2 weeks. Average predialytic BP of at least $140 / 90 \mathrm{~mm} \mathrm{Hg}$ was considered hypertensive, while postdialytic BP of at least 130/80 $\mathrm{mm} \mathrm{Hg}$ was required to call a patient hypertensive [15]. Also, any patient on antihypertensive drugs was considered to be hypertensive.

\section{Treated Hypertension}

Those who were considered to be hypertensive were further categorized into groups based on treatment. Hypertensive patients who were receiving at least one antihypertensive medication were considered to be treated, while those who were hypertensive but on no antihypertensives were considered to be untreated.

\section{Controlled Hypertension}

Among patients receiving antihypertensive drugs, if the ambulatory BP was $<135 / 85 \mathrm{~mm} \mathrm{Hg}$ then the patient's hypertension was considered to be controlled. For pre- and postdialytic readings, thresholds of 140/90 and 130/80 mm Hg were similarly used.

\section{Washout of Antihypertensive Drugs}

Among patients who had ABPM and controlled hypertension $(<135 / 85 \mathrm{~mm} \mathrm{Hg})$, antihypertensive drugs were withdrawn gradually over 3-6 weeks. This was done in the context of ascertaining the eligibility of participants in various interventional studies. Each week, measurements of BP at home were self-recorded by the patients twice a day over 4 days after the mid-week dialysis. Ambulatory BP recordings were also repeated after complete washout of medications. However, if systolic BP self-measured at home was found to be $>150 \mathrm{~mm} \mathrm{Hg}$ further withdrawal of medications was terminated and ambulatory BP was recorded.

\section{Data Analysis}

The first part of the study was cross-sectional. Descriptive statistics for demographic and clinical variables related to the prevalence of hypertension were provided for all three types of BP recordings: ambulatory, and pre- and postdialytic recordings. Race was combined into two categories, African-American and nonAfrican-American. Dialysis vintage was categorized into three groups, dialysis $<1$ year, dialysis of $1-4$ years and dialysis of $>4$ years. The number of antihypertensives was capped at 4 , as generally few patients were on $>4$ medications. Differences in the prevalence, treatment and the lack of control of hypertension between techniques were assessed using the $\chi^{2}$ test. Odds ratios (OR) based on logistic regression for each covariate were computed and confidence intervals (CI) were calculated. Variables with OR with $\mathrm{p}<0.2$ were considered for multivariate analysis. Stepwise forward-selection logistic regression was performed with factors added at the 0.15 level of significance. Similar models were fitted for the treatment and control of hypertension for each of the three types of BP recordings.

Next, logistic regression models were constructed with each of the two markers of volume (IVC and LA diameters) used separately to predict the lack of control of hypertension. Lack of control of hypertension was defined as interdialytic ambulatory BP $\geq 135 / 85 \mathrm{~mm} \mathrm{Hg}$ whether the patients received antihypertensive drugs or not. An unadjusted model was first created in which IVC diameter in expiration was the predictor variable and the lack of

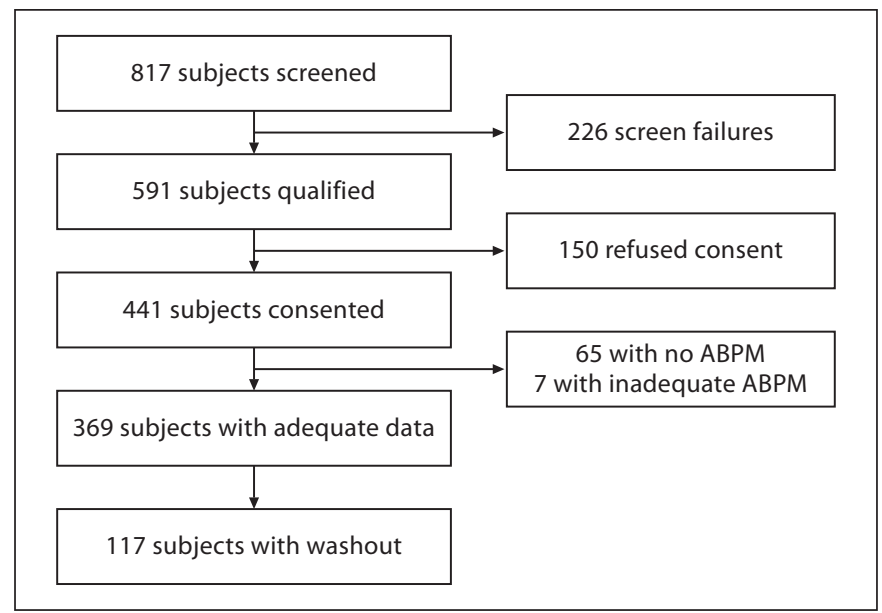

Fig. 1. Participant flow for the cohort study. Screen failures were for a variety of reasons, e.g. morbid obesity or atrial fibrillation. A list of possible reasons appears as exclusion criteria in the Methods section. Of the 369 participants, LA diameter was available in 304 patients and IVC diameter in 290 patients. Pre- and postdialytic $\mathrm{BP}$ recordings were missing in 7 patients.

control of hypertension as the outcome. A second model was then created in which the known demographic and clinical determinants of control of hypertension were used. A third model was created where both the first and the second model were combined. Since the first two models were nested within the third, a likelihood ratio (LR) test was used to compare the nested models.

The second part of the analysis was longitudinal: after washout of antihypertensive agents, the lack of control of hypertension was examined. The threshold of $\geq 135 / 85 \mathrm{~mm} \mathrm{Hg}$ on 44 -hour ambulatory BP recordings was used to define lack of control of hypertension. As above, three models were created. The first model was an unadjusted model with IVC diameter in expiration as the predictor variable and the lack of control of hypertension after washout as the outcome. The second model included the number of antihypertensive medications at baseline and use of antihypertensive medications at washout. A third model was then created where both the first and the second model were combined. Since the first two models were nested within the third, an LR test was used to compare the nested models.

All analyses were conducted using Stata 11.0 (Stata Corp., College Station, Tex., USA). The p values reported are two-sided and taken to be significant at $\mathrm{p}<0.05$.

\section{Results}

The study flow is shown in figure 1. The epidemiology of hypertension is described using 369 patients who had adequate a mbulatory BP recordings. The mean number of ambulatory BP measurements was $93 \pm 23$ per patient over $39 \pm 7.4 \mathrm{~h}$. The mean number of pre- or postdialytic 
Table 1. Descriptive characteristics of the study population and bivariate OR for the prevalence of hypertension

\begin{tabular}{|c|c|c|c|c|c|c|c|c|}
\hline Characteristics & \multicolumn{4}{|l|}{ By АBРM } & \multicolumn{4}{|c|}{ By pre-HD BP } \\
\hline Age, years & $54.2 \pm 12.5$ & $57.5 \pm 14.2$ & $0.98(0.96-1.00)$ & 0.06 & $54.5 \pm 12.7$ & $58.5 \pm 13.9$ & $0.98(0.95-1.00)$ & 0.09 \\
\hline Males & $198(65 \%)$ & $42(64 \%)$ & $1.08(0.62-1.88)$ & 0.8 & $212(65 \%)$ & $23(68 \%)$ & $0.87(0.41-1.86)$ & 0.7 \\
\hline \multicolumn{9}{|l|}{ Racial category } \\
\hline History of smoking & & & & 0.6 & & & & 0.4 \\
\hline Current & $99(33 \%)$ & $21(32 \%)$ & $1.18(0.61-2.27)$ & 0.6 & $104(32 \%)$ & $14(41 \%)$ & $0.80(0.35-1.85)$ & 0.6 \\
\hline Past & $102(34 \%)$ & $18(27 \%)$ & $1.42(0.72-2.79)$ & 0.3 & $110(34 \%)$ & $8(24 \%)$ & $1.48(0.57-3.83)$ & 0.4 \\
\hline Never & $92(30 \%)$ & $23(35 \%)$ & 1.00 (ref. cat.) & & $102(31 \%)$ & $11(32 \%)$ & 1.00 (ref. cat.) & \\
\hline History of cardiovascular disease & $104(34 \%)$ & $24(36 \%)$ & $0.86(0.49-1.51)$ & 0.6 & $114(35 \%)$ & $11(32 \%)$ & $1.03(0.48-2.21)$ & 0.9 \\
\hline Pre-HD weight, kg & $83.8 \pm 19.5$ & $89.2 \pm 23.1$ & $0.99(0.97-1.00)$ & 0.05 & $84.8 \pm 20.3$ & $84.4 \pm 19.9$ & $1.00(0.98-1.02)$ & 0.9 \\
\hline Post-HD weight, $\mathrm{kg}$ & $80.7 \pm 18.7$ & $85.5 \pm 22.5$ & $0.99(0.97-1.00)$ & 0.07 & $81.8 \pm 19.6$ & $81.8 \pm 19.2$ & $1.00(0.98-1.02)$ & 1 \\
\hline BMI & $27.4 \pm 5.7$ & $29.1 \pm 6.4$ & $0.95(0.91-1.00)$ & 0.04 & $27.7 \pm 5.9$ & $27.8 \pm 5.9$ & $1.00(0.94-1.06)$ & 0.9 \\
\hline \multicolumn{9}{|l|}{ Etiology of end-stage renal disease } \\
\hline Diabetes mellitus & $110(36 \%)$ & $18(27 \%)$ & 1.00 (ref. cat.) & 0.5 & $119(36 \%)$ & $8(24 \%)$ & 1.00 (ref. cat.) & 0.5 \\
\hline Hypertensive nephrosclerosis & $144(48 \%)$ & $31(47 \%)$ & $0.76(0.40-1.43)$ & 0.4 & $153(47 \%)$ & $18(53 \%)$ & $0.57(0.24-1.36)$ & 0.2 \\
\hline Glomerulonephritis & $16(5 \%)$ & $3(5 \%)$ & $0.87(0.23-3.30)$ & 0.8 & $16(5 \%)$ & $3(9 \%)$ & $0.36(0.09-1.49)$ & 0.2 \\
\hline Adult autosomal polycystic kidney disease & $4(1 \%)$ & $2(3 \%)$ & $0.33(0.06-1.92)$ & 0.2 & $5(2 \%)$ & $1(3 \%)$ & $0.34(0.03-3.23)$ & 0.3 \\
\hline Other & $25(8 \%)$ & $8(12 \%)$ & $0.51(0.20-1.31)$ & 0.2 & $30(9 \%)$ & $2(6 \%)$ & $1.01(0.20-5.00)$ & 1 \\
\hline Urea reduction ratio, \% & $74.3 \pm 7.3$ & $74.5 \pm 7.8$ & $1.00(0.96-1.04)$ & 0.8 & $74.2 \pm 7.5$ & $74.8 \pm 5.4$ & $0.99(0.94-1.04)$ & 0.7 \\
\hline Serum albumin, g/dl & $3.7 \pm 0.4$ & $3.6 \pm 0.4$ & $1.55(0.84-2.85)$ & 0.2 & $3.7 \pm 0.4$ & $3.6 \pm 0.4$ & $1.49(0.64-3.43)$ & 0.4 \\
\hline Aspirin use & $135(45 \%)$ & $20(30 \%)$ & $1.77(0.99-3.14)$ & 0.05 & $140(43 \%)$ & $11(32 \%)$ & $1.57(0.74-3.32)$ & 0.2 \\
\hline Statin use & $131(43 \%)$ & $20(30 \%)$ & $1.68(0.94-2.98)$ & 0.08 & $136(41 \%)$ & $12(35 \%)$ & $1.31(0.62-2.73)$ & 0.5 \\
\hline Vitamin D receptor activator use & $108(36 \%)$ & $18(27 \%)$ & $1.42(0.78-2.56)$ & 0.3 & $115(35 \%)$ & $10(29 \%)$ & $1.30(0.60-2.82)$ & 0.5 \\
\hline Epoetin use & $165(54 \%)$ & $21(32 \%)$ & $2.45(1.39-4.32)$ & $<0.01$ & $172(52 \%)$ & $11(32 \%)$ & $2.32(1.10-4.91)$ & 0.03 \\
\hline
\end{tabular}

Pre-and postdialysis BP recordings were missing in 7 patients.

BP measurements was $5.1 \pm 1.5$ per patient. LA diameter was available in 304 patients and IVC diameter in 290 patients.

The mean prescribed dialysis time was $236 \pm 18 \mathrm{~min}$, while the mean amount of dialysis actually delivered was $232 \pm 23 \mathrm{~min}$. Among the 349 patients with access information available, $165(47 \%)$ used a fistula, $81(23 \%)$ had a graft and 103 (30\%) used a catheter. Of 325 patients with information on residual renal function available, 264 (81\%) had no residual renal function $(<50 \mathrm{ml} /$ interdialytic period), 22 (7\%) showed little residual function (50$200 \mathrm{ml} /$ interdialytic period), while 39 (12\%) displayed high residual renal function $(>200 \mathrm{ml} /$ interdialytic period). Of the 360 patients in whom dialysate sodium was 


\begin{tabular}{|c|c|c|c|c|}
\hline \multicolumn{4}{|c|}{ By post-HD BP } & \multirow[t]{2}{*}{ Total } \\
\hline yes & no & OR (95\% CI) & $\mathrm{p}$ value & \\
\hline $313(86 \%)$ & $49(14 \%)$ & & & $369(100 \%)$ \\
\hline $54.4 \pm 12.7$ & $58.0 \pm 13.9$ & $0.98(0.96-1.00)$ & 0.07 & $54.8 \pm 12.9$ \\
\hline 204 (65\%) & $31(63 \%)$ & $1.09(0.58-2.03)$ & 0.8 & $240(65 \%)$ \\
\hline $51(16 \%)$ & $4(8 \%)$ & 1.00 (ref. cat.) & & 57 (15\%) \\
\hline \multirow[t]{2}{*}{$262(84 \%)$} & 45 (92\%) & $0.46(0.16-1.33)$ & 0.1 & $312(85 \%)$ \\
\hline & & & 0.6 & \\
\hline $100(32 \%)$ & $18(37 \%)$ & $0.98(0.48-2.02)$ & 1 & $120(33 \%)$ \\
\hline $105(34 \%)$ & $13(27 \%)$ & $1.43(0.66-3.10)$ & 0.4 & $120(33 \%)$ \\
\hline $96(31 \%)$ & $17(35 \%)$ & 1.00 (ref. cat.) & & $115(31 \%)$ \\
\hline $108(35 \%)$ & $17(35 \%)$ & $0.94(0.50-1.79)$ & 0.9 & $128(35 \%)$ \\
\hline $162(52 \%)$ & $17(35 \%)$ & $1.97(1.05-3.70)$ & 0.04 & $180(49 \%)$ \\
\hline $122(39 \%)$ & $8(16 \%)$ & 1.00 (ref. cat.) & $<0.01$ & $134(36 \%)$ \\
\hline $117(37 \%)$ & $18(37 \%)$ & $0.43(0.18-1.02)$ & 0.05 & $135(37 \%)$ \\
\hline 73 (23\%) & $22(45 \%)$ & $0.22(0.09-0.51)$ & $<0.001$ & 97 (26\%) \\
\hline $84.4 \pm 20.3$ & $87.2 \pm 20.2$ & $0.99(0.98-1.01)$ & 0.4 & $84.8 \pm 20.2$ \\
\hline $81.4 \pm 19.5$ & $84.3 \pm 19.5$ & $0.99(0.98-1.01)$ & 0.3 & $81.5 \pm 19.5$ \\
\hline $27.5 \pm 5.8$ & $29.2 \pm 6.2$ & $0.95(0.91-1.00)$ & 0.07 & $27.7 \pm 5.9$ \\
\hline $114(36 \%)$ & $13(27 \%)$ & 1.00 (ref. cat.) & 0.6 & $128(35 \%)$ \\
\hline $143(46 \%)$ & $28(57 \%)$ & $0.58(0.29-1.18)$ & 0.1 & $175(47 \%)$ \\
\hline $16(5 \%)$ & $3(6 \%)$ & $0.61(0.16-2.37)$ & 0.5 & $19(5 \%)$ \\
\hline $5(2 \%)$ & $1(2 \%)$ & $0.57(0.06-5.26)$ & 0.6 & $6(2 \%)$ \\
\hline $29(9 \%)$ & $3(6 \%)$ & $1.10(0.29-4.13)$ & 0.9 & $33(9 \%)$ \\
\hline $74.3 \pm 7.4$ & $74.1 \pm 6.6$ & $1.00(0.96-1.05)$ & 0.9 & $74.3 \pm 7.4$ \\
\hline $3.7 \pm 0.4$ & $3.6 \pm 0.4$ & $1.45(0.72-2.93)$ & 0.3 & $3.7 \pm 0.4$ \\
\hline $12.1 \pm 1.4$ & $12.3 \pm 1.8$ & $0.93(0.75-1.15)$ & 0.5 & $12.1 \pm 1.5$ \\
\hline $266(85 \%)$ & 0 & & & $270(73 \%)$ \\
\hline $46(15 \%)$ & $48(98 \%)$ & & & $96(26 \%)$ \\
\hline $66(21 \%)$ & 0 & & & $68(18 \%)$ \\
\hline $86(27 \%)$ & 0 & & & $86(23 \%)$ \\
\hline $55(18 \%)$ & 0 & & & 57 (15\%) \\
\hline 59 (19\%) & 0 & & & $59(16 \%)$ \\
\hline $137(44 \%)$ & $14(29 \%)$ & $1.96(1.01-3.78)$ & 0.05 & $155(42 \%)$ \\
\hline $132(42 \%)$ & $16(33 \%)$ & $1.51(0.80-2.86)$ & 0.2 & $151(41 \%)$ \\
\hline $110(35 \%)$ & $15(31 \%)$ & $1.23(0.64-2.37)$ & 0.5 & $126(34 \%)$ \\
\hline $167(53 \%)$ & $16(33 \%)$ & $2.38(1.26-4.49)$ & $<0.01$ & $186(50 \%)$ \\
\hline
\end{tabular}

available, 192 (53\%) used a constant profile, with a mean sodium of $139.8 \pm 2.2$, while $168(47 \%)$ used some sort of variable profile, linear, exponential, or in a few cases stepwise. There was a strong correlation between sodium prescription and the dialysis unit $(\mathrm{p}<0.001)$.

Table 1 shows the prevalence of hypertension using three different BP recordings. The prevalence of hyper- tension was $82 \%$ by ambulatory $\mathrm{BP}, 91 \%$ by predialytic BP, and $86 \%$ by postdialytic BP recordings ( $\mathrm{p}=0.004$ for differences in prevalence). Significant bivariate determinants of prevalence for ambulatory hypertension were a lower BMI and more aspirin or epoetin use. For predialytic hypertension, the risk factors were fewer years on dialysis and epoetin use. For postdialytic hypertension, the risk factors were a history of diabetes mellitus, fewer years on dialysis, aspirin use, and epoetin use. Thus, epoetin use was associated with greater prevalence of hypertension regardless of the method of BP measurement.

The treatment and control of hypertension using each of the three different BP recordings are shown in supplementary tables 1 and 2 (for all suppl. material, see www. karger.com/doi/10.1159/000331067). Treatment rates according to hypertension diagnosed by various techniques was as follows: $89 \%$ by ABPM, $81 \%$ by pre-, and $85 \%$ by postdialytic BP recordings (suppl. table $1 ; \mathrm{p}=0.019$ for differences in treatment). Among the treated patients, $38 \%$ were controlled by ambulatory BP, $22 \%$ by pre-, and $31 \%$ by postdialytic BP recordings (suppl. table 2 ; $\mathrm{p}<$ 0.001 for differences in control).

The multivariate determinants of prevalence, treatment, and control of hypertension are shown in table 2 . Dialysis vintage was an independent predictor of prevalence of hypertension regardless of the measurement method; more years on dialysis were associated with a lower prevalence of hypertension. Both lower BMI and epoetin use were independent determinants of prevalence of hypertension by ABPM and postdialytic BP recordings but not by predialytic recordings.

The independent determinants for treatment of hypertension regardless of the BP measurement method were aspirin use and vitamin $\mathrm{D}$ receptor activator use. More aspirin use was associated with twofold or higher odds of treatment, and more vitamin $\mathrm{D}$ receptor activator use was associated with half or lower odds of pharmacological treatment of hypertension. Epoetin use was associated with at least twofold greater odds for treatment when $\mathrm{BP}$ was assessed using pre- or postdialytic BP but not ambulatory BP recordings. A higher BMI was associated with lower odds of pharmacological treatment when $\mathrm{BP}$ was assessed using predialytic BP only.

The lack of control of hypertension when assessed by ABPM was associated with the following variables: lower serum albumin, greater antihypertensive drug use, and vitamin $\mathrm{D}$ receptor activator use. The lack of control of hypertension when assessed by predialytic BP monitoring was associated with the following variables: lower BMI, history of diabetes mellitus, and lower hemoglobin. 
Table 2. Multivariate ORs for prevalence, treatment and lack of control of hypertension

\begin{tabular}{|c|c|c|c|c|c|c|}
\hline \multirow[t]{2}{*}{ Determinants } & \multicolumn{2}{|l|}{ ABPM } & \multicolumn{2}{|l|}{ Pre-HD BP } & \multicolumn{2}{|l|}{ Post-HD BP } \\
\hline & OR (95\% CI) & $\mathrm{p}$ value & OR (95\% CI) & $\mathrm{p}$ value & OR (95\% CI) & $\mathrm{p}$ value \\
\hline \multicolumn{7}{|l|}{ Prevalence of hypertension } \\
\hline Age, years & $0.98(0.96-1.00)$ & 0.08 & & & & \\
\hline Serum albumin, g/dl & $1.76(0.90-3.46)$ & 0.1 & & & & \\
\hline Aspirin use, yes/no & $1.85(0.98-3.51)$ & 0.06 & & & $2.01(0.97-4.17)$ & 0.06 \\
\hline BMI & $0.91(0.87-0.97)$ & $<0.01$ & & & $0.92(0.86-0.98)$ & $<0.01$ \\
\hline Dialysis duration & & 0.03 & & 0.01 & & $<0.001$ \\
\hline$<1$ year & 1.00 (ref. cat.) & & 1.00 (ref. cat.) & & 1.00 (ref. cat.) & \\
\hline $1-4$ years & $0.48(0.22-1.02)$ & 0.06 & $0.21(0.06-0.77)$ & 0.02 & $0.30(0.12-0.79)$ & 0.01 \\
\hline$\geq 4$ years & $0.36(0.17-0.78)$ & 0.01 & $0.14(0.04-0.51)$ & $<0.01$ & $0.15(0.06-0.39)$ & $<0.001$ \\
\hline Epoetin use, yes/no & $2.54(1.35-4.77)$ & $<0.01$ & $2.06(0.91-4.69)$ & 0.08 & $2.16(1.06-4.40)$ & 0.03 \\
\hline $\operatorname{LR} \chi^{2}$ & 30.76 & & 16.00 & & 29.42 & \\
\hline Pseudo $r^{2}$ & 0.10 & & 0.08 & & 0.11 & \\
\hline \multicolumn{7}{|l|}{ Treatment of hypertension } \\
\hline Aspirin use, yes/no & $2.50(1.11-5.64)$ & 0.03 & $2.43(1.30-4.53)$ & $<0.01$ & $2.08(1.05-4.09)$ & 0.03 \\
\hline BMI & & & $0.93(0.88-0.97)$ & $<0.01$ & $0.95(0.90-1.01)$ & 0.08 \\
\hline Epoetin use, yes/no & & & $2.17(1.17-4.03)$ & 0.01 & $2.02(1.02-3.99)$ & 0.04 \\
\hline Vitamin D receptor activator use, yes/no & $0.39(0.19-0.82)$ & 0.01 & $0.51(0.27-0.95)$ & 0.03 & $0.48(0.24-0.94)$ & 0.03 \\
\hline $\operatorname{LR} \chi^{2}$ & 10.88 & & 23.71 & & 13.11 & \\
\hline Pseudo $r^{2}$ & 0.05 & & 0.07 & & 0.05 & \\
\hline \multicolumn{7}{|l|}{ Lack of control of hypertension } \\
\hline Serum albumin, $\mathrm{g} / \mathrm{dl}$ & $0.38(0.20-0.72)$ & $<0.01$ & & & & \\
\hline BMI & & & $0.91(0.86-0.97)$ & $<0.01$ & & \\
\hline Epoetin use, yes/no & & & & & $1.88(1.05-3.34)$ & 0.03 \\
\hline Antihypertensive use & & 0.02 & & & & $<0.01$ \\
\hline 1 antihypertensive & 1.00 (ref. cat.) & & & & 1.00 (ref. cat.) & \\
\hline 2 antihypertensives & $1.53(0.75-3.13)$ & 0.2 & & & $3.07(1.46-6.45)$ & $<0.01$ \\
\hline 3 antihypertensives & $2.49(1.10-5.64)$ & 0.03 & & & $3.76(1.61-8.77)$ & $<0.01$ \\
\hline$\geq 4$ antihypertensives & $3.21(1.41-7.30)$ & $<0.01$ & & & $4.52(1.92-10.67)$ & $<0.001$ \\
\hline History of diabetes mellitus, yes/no & & & $3.46(1.72-6.99)$ & $<0.001$ & & \\
\hline Hemoglobin, g/dl & & & $0.77(0.60-0.97)$ & 0.03 & & \\
\hline Urea reduction ratio, $\%$ & & & & & $1.04(1.00-1.09)$ & 0.04 \\
\hline Vitamin D receptor activator use, yes/no & $1.88(1.02-3.46)$ & 0.04 & & & & \\
\hline $\operatorname{LR} \chi^{2}$ & 23.71 & & 21.36 & & 22.09 & \\
\hline Pseudo $r^{2}$ & 0.07 & & 0.08 & & 0.07 & \\
\hline
\end{tabular}

The lack of control of hypertension when assessed by postdialytic BP monitoring was associated with the following variables: epoetin use, greater antihypertensive drug use, and a greater urea reduction ratio. Neither residual renal function nor interdialytic weight gain was associated with prevalence, treatment, or control of hypertension (data not shown).

The echocardiographic LA diameter indexed for body surface area was $2.16 \pm 0.45 \mathrm{~cm} / \mathrm{m}^{2}(2.12 \pm 0.45$ among those controlled and $2.19 \pm 0.44$ among those not controlled, $\mathrm{p}=0.2)$. The IVC diameter in expiration indexed for body surface area was $8.04 \pm 3.16 \mathrm{~mm} / \mathrm{m}^{2}(7.61 \pm$ 3.04 among those controlled and $8.40 \pm 3.21$ among those not controlled, $\mathrm{p}=0.03$ ). Table 3 shows the $\mathrm{OR}$ for the lack of control of hypertension for the IVC diameter. This analysis was restricted to the subgroup of 277 patients on whom we had information on IVC diameter (290 patients), antihypertensive drug use (290 patients), 
Table 3. Association of volume markers on hypertension by ambulatory BP

\begin{tabular}{|c|c|c|c|c|c|}
\hline \multirow[t]{2}{*}{ Determinants } & \multirow{2}{*}{$\frac{\text { Model } 1}{\text { OR (95\% CI) }}$} & \multicolumn{2}{|l|}{ Model 2} & \multicolumn{2}{|l|}{ Model 3} \\
\hline & & OR (95\% CI) & $\mathrm{p}$ value & OR (95\% CI) & $\mathrm{p}$ value \\
\hline IVC expiration index, $\mathrm{mm} / \mathrm{m}^{2}$ & $1.09(1.00,1.18)^{*}$ & & & $1.13(1.03-1.23)$ & 0.01 \\
\hline Serum albumin, g/dl & & $0.73(0.40-1.30)$ & 0.3 & $0.76(0.42-1.38)$ & 0.4 \\
\hline Antihypertensive use & & & $<0.0001$ & & $<0.0001$ \\
\hline 0 antihypertensives & & 1.00 (ref. cat.) & & 1.00 (ref. cat.) & \\
\hline 1 antihypertensive & & $1.40(0.66-2.96)$ & 0.4 & $1.41(0.66-3.00)$ & 0.4 \\
\hline 2 antihypertensives & & $3.15(1.52-6.53)$ & $<0.01$ & $3.19(1.52-6.70)$ & $<0.01$ \\
\hline 3 antihypertensives & & $4.85(2.06-11.43)$ & $<0.001$ & $5.28(2.21-12.61)$ & $<0.001$ \\
\hline$\geq 4$ antihypertensives & & $5.24(2.31-11.92)$ & $<0.0001$ & $5.58(2.42-12.88)$ & $<0.0001$ \\
\hline Vitamin D receptor activator use, yes/no & & $2.78(1.56-4.97)$ & $<0.001$ & $3.07(1.70-5.55)$ & $<0.001$ \\
\hline $\operatorname{LR} \chi^{2}$ & 4.10 & 40.87 & & 47.97 & \\
\hline Pseudo $r^{2}$ & 0.01 & 0.11 & & 0.13 & \\
\hline LR test vs. model 1 & & & & & $<0.0001$ \\
\hline LR test vs. model 2 & & & & & $<0.01$ \\
\hline
\end{tabular}

serum albumin (277 patients) and vitamin $\mathrm{D}$ receptor activator use (290 patients). Each $1 \mathrm{~mm} / \mathrm{m}^{2}$ increase in IVC diameter was associated with $9 \%$ increased odds for worse hypertension control by ABPM (model 1). In a model to predict lack of hypertension control that included serum albumin, number of antihypertensive agents, and vitamin $\mathrm{D}$ receptor activator drugs, all covariates except serum albumin were significant (model 2). When the two models were combined, the OR of IVC diameter in expiration indexed for body surface area remained significant (model 3). Model 3 was superior to either model 1 or model 2 by the LR test. The OR for LA diameter was not significant either before or after adjustment (data not shown).

Among the 117 patients who underwent withdrawal of antihypertensive drugs, 92 had echocardiographic data available. The baseline characteristics of these patients are shown in supplementary table 3 . The LA diameter indexed for body surface area was $2.15 \pm 0.46 \mathrm{~cm} / \mathrm{m}^{2}(2.05$ \pm 0.58 among those controlled and $2.17 \pm 0.43$ among those not controlled, $\mathrm{p}=0.33$ ). The IVC diameter in expiration indexed for body surface area was $7.5 \pm 2.4$ $\mathrm{mm} / \mathrm{m}^{2}(7.8 \pm 2.5$ among those not controlled and $6.4 \pm$ 1.5 among those controlled, $\mathrm{p}=0.02$ ). Table 4 shows the OR for lack of control of hypertension for the IVC diameter in expiration for washout. Each $1 \mathrm{~mm} / \mathrm{m}^{2}$ increase in IVC diameter was associated with $39 \%$ increased odds for worse hypertension control by ABPM (model 1). Model 2 shows the odds of worse hypertension control were elevated when more antihypertensive drugs were being used at baseline. Model 3 shows the combined models where the OR for worse hypertension control remained significant for IVC diameter in expiration even after adjustment for the number of antihypertensive drugs at baseline and the use of antihypertensive drugs at the end of the washout period. Model 3 was superior to either model 1 or model 2 by the LR test. The OR for LA diameter was not significant either before or after adjustment (data not shown).

\section{Discussion}

The true prevalence of hypertension in end-stage renal disease patients on HD is difficult to ascertain. This is because of the large variation in BP levels obtained before, during or after dialysis and the lack of standard definitions of hypertension. There are several reports which have ascertained the prevalence, treatment, and control of hypertension in such patients using varying definitions of hypertension [1-4]. These studies have largely been performed using BP measurements obtained before and after dialysis. In 2,535 clinically stable, adult HD patients participating in a multicenter trial, the prevalence of hypertension defined by predialytic BP measurements was found to be $86 \%$ [2]. Of these hypertensive patients, 
Table 4. Effects of volume markers on hypertension by ABPM after washout

\begin{tabular}{|c|c|c|c|c|c|c|}
\hline \multirow[t]{2}{*}{ Determinant } & \multicolumn{2}{|l|}{ Model 1} & \multicolumn{2}{|l|}{ Model 2} & \multicolumn{2}{|l|}{ Model 3} \\
\hline & OR $(95 \% \mathrm{CI})$ & $\mathrm{p}$ value & OR (95\% CI) & $\mathrm{p}$ value & OR (95\% CI) & $\mathrm{p}$ value \\
\hline IVC expiration index, $\mathrm{mm} / \mathrm{m}^{2}$ & $1.39(1.04-1.84)$ & 0.02 & & & $1.43(1.05-1.96)$ & 0.02 \\
\hline Initial antihypertensives & & & & 0.02 & & 0.02 \\
\hline 1 antihypertensive & & & 1.00 (ref. cat.) & & 1.00 (ref. cat.) & \\
\hline 2 antihypertensives & & & $1.89(0.53-6.73)$ & 0.3 & $1.88(0.49-7.17)$ & 0.4 \\
\hline 3 antihypertensives & & & $13.42(1.73-103.86)$ & 0.01 & $11.75(1.51-91.18)$ & 0.02 \\
\hline$\geq 4$ antihypertensives & & & $28.88(2.55-327.11)$ & $<0.01$ & $30.57(2.68-348.52)$ & $<0.01$ \\
\hline $\begin{array}{l}\text { Antihypertensive use at } \\
\text { end of washout, yes/no }\end{array}$ & & & $0.26(0.06-1.11)$ & 0.07 & $0.27(0.06-1.16)$ & 0.08 \\
\hline $\operatorname{LR} \chi^{2}$ & 6.44 & & 14.63 & & 21.14 & \\
\hline Pseudo ${ }^{2}$ & 0.07 & & 0.16 & & 0.23 & \\
\hline LR test vs. model 1 & & & & & & $<0.01$ \\
\hline LR test vs. model 2 & & & & & & 0.01 \\
\hline
\end{tabular}

$12 \%$ were untreated, $58 \%$ were treated but not controlled, and only $30 \%$ were controlled. This is in line with other studies which have found the use of antihypertensive drugs to vary between 59 and $83 \%[1,3,4]$. Our study found significant differences in the prevalence of hypertension depending on how hypertension was defined. Using an ABPM threshold of $135 / 85 \mathrm{~mm} \mathrm{Hg}$ to define hypertension or the use of antihypertensive drugs, the prevalence of hypertension was noted to be $82 \%$. Thus, even using ABPM, hypertension appears to be highly prevalent among HD patients.

The risk factors for hypertension in the general population are age, sex, and race. Among HD patients, sex and race were not found to be determinants of hypertension [2]. Thus, men and women, African-Americans and Whites were equally at risk of having hypertension once they were on HD. This was confirmed in this study using ABPM. In contrast to the general population, younger patients were more likely to be hypertensive. This was found to be of borderline significance using ABPM. The independent determinants of hypertension using predialytic $\mathrm{BP}$ measurements have been reported to be a younger age, the etiology of end-stage renal disease (either due to diabetes mellitus or hypertension), absence of obesity, and fewer years on dialysis [2]. In this study, we found that epoetin use, fewer years on dialysis, and a lower BMI were independently associated with prevalent hypertension. The association of epoetin use with hypertension is now well recognized [16]. Mechanisms of increased BP with epoetin include enhanced responsiveness to norepinephrine [17] and increase in endothelin-1 and constrictor prostanoids [18]. The association of fewer years on dialysis with greater hypertension may be due to several reasons. First, it is possible that those with increased hypertension die; therefore, the survivors have lower BP. Although among hemodialysis patients a higher BP is associated with death when BP is assessed using ambulatory monitoring $[7,8]$, the reverse has been found to be the case for pre- or postdialytic measurements $[19,20]$. Second, chronic catecholamine excess may lead to $\beta$-adrenergic receptor downregulation in long-term survivors $[21,22]$. Why a lower BMI is independently associated with a greater prevalence of hypertension is difficult to explain and is a subject of ongoing investigation. First, it is possible that subtle ECFV excess leads to greater hemodynamic response in those who are lean. Obese people may have a greater buffer to sequester ECFV, which may dampen the hemodynamic response. Second, skeletal muscle is an important site for renalase expression, an enzyme that breaks down catecholamines [23]. Sarcopenic patients would therefore have greater circulating catecholamines and therefore greater BP.

Treatment with antihypertensive drugs has been independently associated with the following factors: younger age, diabetes mellitus, lack of obesity, and aspirin use [2]. In our study using ABPM, aspirin use was associated with twofold or greater odds for treatment of hypertension. This result is consistent with prior reports among HD patients [2] but discordant from others [24] which report greater BP increase with epoetin use when antiplatelet agents are not used. It is possible that even low-dose aspirin among HD patients may tilt the balance more in favor 
of vasoconstrictor prostaglandins. The use of vitamin D receptor activators was associated with an $\mathrm{OR} \leq 0.5$ for treatment. Vitamin D receptor activators can have effects on the cardiovascular system, which include regression of left ventricular hypertrophy [25] and lowering of blood pressure [26]; therefore, these results are biologically plausible.

Control of hypertension has been independently associated with the following: white race, absence of diabetes mellitus, longer years on HD, use of aspirin, and less antihypertensive drug use [2]. We confirmed that greater antihypertensive drug use, lower serum albumin, and vitamin $\mathrm{D}$ receptor activator use to be associated with worse hypertension control. The association of greater antihypertensive drug use with worse hypertension control may be because patients with worse hypertension control may have ECFV excess, which makes hypertension difficult to control despite the use of more antihypertensive drugs [9]. The association of lower serum albumin with worse hypertension control may be because of inflammation, malnutrition, and wasting that culminates in subtle, unrecognized, ECFV excess. The association of vitamin $\mathrm{D}$ receptor activator use with worse hypertension control is more difficult to explain. It is possible that vitamin $\mathrm{D}$ receptor activator use may reflect secondary hyperparathyroidism, which consequently may increase vascular smooth muscle calcium and make hypertension more difficult to control $[27,28]$.

The epidemiology of hypertension has changed considerably since the introduction of HD. In the early years of dialysis, low sodium dialysate was prescribed, dietary sodium was restricted, and great attention paid to dry weight [29]. The prevalence of hypertension was then reported to be $10-15 \%$ [29]. The prevalence estimates of $85-90 \%$ currently reported may be due to several factors, such as increased prevalence of diabetes mellitus but also because of changes in dialysis practice over the years. For example, the introduction of higher sodium dialysate and less attention to dietary sodium and dry weight may have contributed to the difficulty in achieving normovolemia. Our study shows that when ECFV is expanded (increased IVC diameter in end-expiration), the odds of poor control of hypertension are increased both in crosssectional and longitudinal analyses, i.e. after washout of antihypertensive drugs. These results are also consistent with the results of the DRIP trial (Dry-Weight Reduction in Hypertensive Hemodialysis Patients), where reduction in dry weight resulted in improvement in interdialytic ambulatory BP as well as reduction in IVC diameter $[13,30]$.

Ambulatory Hypertension and Volemia in HD
Our study has some limitations. We did not study why thinner patients were more hypertensive. Whether thinner patients had weight loss and therefore subtle volume excess was not studied prospectively. However, no crosssectional relationship of BMI with IVC diameter emerged in linear regression analysis $\left(\mathrm{p}=0.7, \mathrm{r}^{2}<0.001\right)$. This does not imply that volume excess may not be causally related to hypertension among HD patients. In fact, in the longitudinal study, IVC diameter was related to the development of hypertension. We acknowledge that the relationship between volume and BP may be nonlinear and complex. Longitudinal and larger studies are needed to better detect and define this relationship. Using ambulatory BP measurements, we have not been able to confirm the existence of the lag phenomenon in the DRIP trial. Our study is cross-sectional and therefore cannot prove or disprove the presence of the lag phenomenon.

The results of this study demonstrate that: (1) hypertension is highly prevalent and difficult to control among HD patients; (2) the prevalence, treatment, and control of hypertension as well as the risk factors associated with them differ substantially based on the definition of these conditions, and (3) the ECFV marker of end-expiration IVC diameter indexed for body surface area is associated with poor control of hypertension both in cross-sectional analyses as well as after washout of antihypertensive drugs. Thus, if hypertension is to be better controlled, standard methods for measurement and control of ECFV would be the initial steps.

References 
6 Agarwal R, Brim NJ, Mahenthiran J, Andersen MJ, Saha C: Out-of-hemodialysis-unit blood pressure is a superior determinant of left ventricular hypertrophy. Hypertension 2006;47:62-68.

$\checkmark 7$ Alborzi P, Patel N, Agarwal R: Home blood pressures are of greater prognostic value than hemodialysis unit recordings. Clin J Am Soc Nephrol 2007;2:1228-1234.

$>8$ Agarwal R: Blood pressure and mortality among hemodialysis patients. Hypertension 2010;55:762-768.

9 Agarwal R, Weir MR: Dry-weight: a concept revisited in an effort to avoid medication-directed approaches for blood pressure control in hemodialysis patients. Clin J Am Soc Nephrol 2010;5:1255-1260.

-10 Agarwal R, Andersen MJ, Bishu K, Saha C: Home blood pressure monitoring improves the diagnosis of hypertension in hemodialysis patients. Kidney Int 2006;69:900-906.

-11 Agarwal R: Supervised atenolol therapy in the management of hemodialysis hypertension. Kidney Int 1999;55:1528-1535.

-12 Sahn DJ, DeMaria A, Kisslo J, Weyman A: Recommendations regarding quantitation in M-mode echocardiography: results of a survey of echocardiographic measurements. Circulation 1978;58:1072-1083.

-13 Agarwal R, Bouldin JM, Light RP, Garg A: Inferior vena cava diameter and left atrial diameter measure volume but not dry weight. Clin J Am Soc Nephrol 2011;6:1066-1072.

-14 Chobanian AV, Bakris GL, Black HR, Cushman WC, Green LA, Izzo JL Jr, Jones DW, Materson BJ, Oparil S, Wright JT Jr, Roccella EJ: The Seventh Report of the Joint National Committee on Prevention, Detection, Evaluation, and Treatment of High Blood Pressure: the JNC 7 report. JAMA 2003;289: 2560-2572.

-15 K/DOQI clinical practice guidelines for cardiovascular disease in dialysis patients. Am J Kidney Dis 2005;45:S1-S153.
16 Krapf R, Hulter HN: Arterial hypertension induced by erythropoietin and erythropoiesis-stimulating agents (ESA). Clin J Am Soc Nephrol 2009;4:470-480.

-17 Hand MF, Haynes WG, Johnstone HA, Anderton JL, Webb DJ: Erythropoietin enhances vascular responsiveness to norepinephrine in renal failure. Kidney Int 1995;48: 806-813.

18 Bode-Boger SM, Boger RH, Kuhn M, Radermacher J, Frolich JC: Recombinant human erythropoietin enhances vasoconstrictor tone via endothelin-1 and constrictor prostanoids. Kidney Int 1996;50:1255-1261.

19 Li Z, Lacson E Jr, Lowrie EG, Ofsthun NJ, Kuhlmann MK, Lazarus JM, Levin NW: The epidemiology of systolic blood pressure and death risk in hemodialysis patients. Am J Kidney Dis 2006;48:606-615.

20 Port FK, Hulbert-Shearon TE, Wolfe RA, Bloembergen WE, Golper TA, Agodoa, LY, Young EW: Predialysis blood pressure and mortality risk in a national sample of maintenance hemodialysis patients. Am J Kidney Dis 1999;33:507-517.

-21 Daul AE, Wang XL, Michel MC, Brodde OE: Arterial hypotension in chronic hemodialyzed patients. Kidney Int 1987;32:728-735.

-22 Esforzado AN, Cases AA, Bono IM, Gaya BJ, Calls GJ, Rivera FF: Autonomic nervous system and adrenergic receptors in chronic hypotensive haemodialysis patients. Nephrol Dial Transplant 1997;12:939-944.

23 Xu J, Li G, Wang P, Velazquez H, Yao X, Li Y, Wu Y, Peixoto A, Crowley S, Desir GV: Renalase is a novel, soluble monoamine oxidase that regulates cardiac function and blood pressure. J Clin Invest 2005;115:1275-1280.

24 Caravaca F, Pizarro JL, Arrobas M, Cubero JJ, Garcia MC, Perez-Miranda M: Antiplatelet therapy and development of hypertension induced by recombinant human erythropoietin in uremic patients. Kidney Int 1994;45: 845-851.
25 Bodyak N, Ayus JC, Achinger S, Shivalingappa V, Ke Q, Chen YS, Rigor DL, Stillman I, Tamez H, Kroeger PE, Wu-Wong RR, Karumanchi SA, Thadhani R, Kang PM: Activated vitamin $\mathrm{D}$ attenuates left ventricular abnormalities induced by dietary sodium in Dahl salt-sensitive animals. Proc Natl Acad Sci USA 2007;104:16810-16815.

-26 de Zeeuw D, Agarwal R, Amdahl M, Audhya $\mathrm{P}$, Coyne D, Garimella T, Parving $\mathrm{HH}$, Pritchett Y, Remuzzi G, Ritz E, Andress D: Selective vitamin $\mathrm{D}$ receptor activation with paricalcitol for reduction of albuminuria in patients with type 2 diabetes (VITAL study): a randomised controlled trial. Lancet 2010; 376:1543-1551.

-27 Raine AEG, Bedford L, Simpson AWM, Ashley CC, Brown R, Woodhead JS, Ledingham JGG: Hyperparathyroidism, platelet intracellular free calcium and hypertension in chronic renal failure. Kidney Int 1993;43: 700-705.

$>28$ Goldsmith DJA, Covic AA, Venning MC, Ackrill P: Blood pressure reduction after parathyroidectomy for secondary hyperparathyroidism: further evidence implicating calcium homeostasis in blood pressure regulation. Am J Kidney Dis 1996;27:819825 .

29 Vertes V, Cangiano JL, Berman LB, Gould A: Hypertension in end-stage renal disease. $\mathrm{N}$ Engl J Med 1969;280:978-981.

-30 Satyan S, Light RP, Agarwal R: Relationships of N-terminal pro-B-natriuretic peptide and cardiac troponin $\mathrm{T}$ to left ventricular mass and function and mortality in asymptomatic hemodialysis patients. Am J Kidney Dis 2007;50:1009-1019. 